\title{
A liderança do enfermeiro na estratégia saúde da família: revisão integrativa
}

\author{
The nurse's leadership in the family health strategy: an integrative review
}

El liderazgo de la enfermera en la estrategia de salud familiar: una revisión integradora

Juliane Shuvartz Florêncio Araújo ${ }^{1 *}$, Lucas Nascimento Belo da Costa ${ }^{1}$, Nathalia de Almeida Paiva Pinto Goulart ${ }^{1}$, Thalita Alves de Carvalho ${ }^{1}$, Elaine Lutz Martins², Tarciso Feijó da Silva².

\section{RESUMO}

Objetivo: Identificar nas principais bases de dados os entraves evidenciados e os facilitadores do processo de liderança pelo enfermeiro na Estratégia Saúde da Família. Métodos: Revisão integrativa da literatura realizada através dos descritores "Enfermagem", "Liderança" e "Estratégia Saúde da Família" nas Base de dados da LILACS, MEDLINE, BDENF e SciELO. Resultados: A liderança pelo enfermeiro emergiu em todos os artigos selecionados, elucidando a relevância desse profissional como responsável por orientar e direcionar processos de trabalho. A comunicação, as relações interpessoais, a sobrecarga de trabalho, a autonomia e a educação permanente foram considerados elementos chave para o exercício da liderança, sendo identificados ora como facilitadores ora como entraves. Considerações finais: Os achados do estudo sinalizam a necessidade de novas pesquisas de base qualitativa na perspectiva de compreender, não só como a liderança do enfermeiro na Estratégia de Saúde da Família tem se conformado, mas, se os entraves e facilitadores encontrados na literatura persistem na atualidade.

Palavras-chave: Estratégia saúde da família, Liderança, Enfermagem.

\begin{abstract}
Objective: To identify in the main databases the obstacles evidenced and the facilitators of the leadership process by nurses in the Family Health Strategy. Methods: Integrative literature review carried out using the descriptors "Nursing", "Leadership" and "Family Health Strategy" in the LILACS, MEDLINE, BDENF and SciELO databases. Results: The leadership by the nurse emerged in all selected articles, elucidating the relevance of this professional as responsible for guiding and directing work processes. Communication, interpersonal relationships, work overload, autonomy and permanent education were considered key elements for the exercise of leadership, being identified either as facilitators or as obstacles. Final considerations: The study's findings signal the need for new qualitative research in order to understand, not only how the nurse's leadership in the Family Health Strategy has been conformed, but if the obstacles and facilitators found in the literature persist in the present.
\end{abstract}

Keywords: Family health strategy, Leadership, Nursing.

\section{RESUMEN}

Objetivo: Identificar en las principales bases de datos los obstáculos evidenciados y los facilitadores del proceso de liderazgo de las enfermeras en la Estrategia de Salud Familiar. Métodos: Revisión integral de la literatura realizada con los descriptores "Enfermería", "Liderazgo" y "Estrategia de salud familiar" en las bases

1 Universidade Estácio de Sá (UNESA), Rio de Janeiro - RJ.

*E-mail: shuvartzj@gmail.com

2 Universidade do Estado do Rio de Janeiro (UERJ), Rio de Janeiro - RJ.

SUBMETIDO EM: 6/2020

ACEITO EM: 7/2020

PUBLICADO EM: 8/2020

REAS/EJCH | Vol.Sup.n.58 | e4326 | DOI: https://doi.org/10.25248/reas.e4326.2020 Página 1 de 10 
de datos LILACS, MEDLINE, BDENF y SciELO. Resultados: El liderazgo de la enfermera surgió en todos los artículos seleccionados, aclarando la relevancia de este profesional como responsable de guiar y dirigir los procesos de trabajo. La comunicación, las relaciones interpersonales, la sobrecarga de trabajo, la autonomía y la educación permanente se consideraron elementos clave para el ejercicio del liderazgo, identificándose como facilitadores o como obstáculos. Consideraciones finales: Los hallazgos del estudio señalan la necesidad de una nueva investigación cualitativa para comprender, no solo cómo se ha conformado el liderazgo de la enfermera en la Estrategia de Salud Familiar, sino también si los obstáculos y facilitadores encontrados en la literatura persisten presente.

Palabras clave: Estrategia de salud familiar, Liderazgo, Enfermería.

\section{INTRODUÇÃO}

Na década de 90 buscando melhorias para as condições de saúde dos usuários, o Programa de Agentes Comunitários de Saúde (PACS) foi implantado inicialmente nas regiões norte e nordeste. Esse antecedeu o Programa Saúde da Família (PSF) concebido em 1994 como parte de uma estratégia maior de mudança do modelo de Atenção Primária à Saúde (APS), principalmente no período 1998-2006 (PINTO LF, GIOVANELLA L, 2018).

As mudanças foram factíveis e o PSF deixou de ser um programa que operacionalizava uma política de focalização da APS em populações excluídas do uso dos serviços, passando a ser considerado como uma estratégia de reorientação do modelo de atenção em saúde em 2006 (TEIXEIRA CF, 2006).

A Estratégia de Saúde da Família (ESF) emerge em 2006 como substituta para o PSF na perspectiva de reorientar a APS, sendo constituída por equipes multiprofissionais em função da realidade epidemiológica, institucional e das necessidades de saúde da população (BRASIL, 2017).

No contexto da ESF o enfermeiro, regulamentado pela Lei no 7.498 do exercício profissional (BRASIL, 1986), tem sido fundamental para o cuidado em saúde, assim como para organização dos serviços assumindo dentre outras atribuições a elaboração de planos de cuidados junto aos membros da equipe, realização do planejamento e gerenciamento, supervisão e avaliação dos profissionais de nível médio e das ações voltadas para gestão e liderança (BRASIL, 2017).

A liderança em uma dada estrutura social decorre da distribuição de autoridade para tomada de decisão. Assim, o grau em que uma pessoa demonstra qualidades de liderança depende não somente de suas próprias características individuais, mas também das características da situação ao qual se encontra (CHIAVENATO I, 2014).

No dicionário Aurélio da Língua Portuguesa líder é aquele "que lidera determinado setor de atividade ou uma competição; pessoa que exerce influência sobre o comportamento, pensamento ou opinião dos outros" (FERREIRA ABH, 2010). Espera-se capacidade deste para se adaptar a situação, adotando diferentes estilos de liderança atendendo assim as expectativas de seus liderados e da empresa em situações distintas em consonância com o momento vivido (KURCGANT P, et al., 1996).

Depreende-se, daí a relevância de um líder para determinado grupo de pessoas, gerando motivação e direção para que alcancem não somente suas metas ou objetivos pessoais, mas também, as metas do coletivo. Na APS orientada pela ESF a liderança é percebida como uma ação complexa em seu desenvolvimento e o líder nesse cenário estabelece naturalmente múltiplas interações na coletividade, atuando de maneira diferenciada sentindo, pressentindo, vivenciando, relacionando-se e influenciando os outros.

A conformação da APS no Brasil realça a posição ocupada pelo enfermeiro, aponta-o como protagonista na condução do processo de trabalho e permite identificar que a liderança exercida por ele nos diferentes cenários não segue um padrão previamente determinado. Com isso, elencar os aspectos que interferem na dinâmica cotidiana dos serviços em saúde e que influem na liderança do enfermeiro na Estratégia de Saúde da Família faz-se necessário. Neste sentido, o objetivo deste artigo foi identificar na literatura os entraves evidenciados e os facilitadores do processo de liderança pelo enfermeiro na Estratégia Saúde da Família. 


\section{MÉTODOS}

Este estudo utilizou como metodologia a revisão integrativa da literatura, na qual é possível realizara síntese sobre o conhecimento acerca de determinado assunto, a partir da unificação dos resultados obtidos. Para atender ao objetivo do estudo, foi realizado um levantamento das publicações científicas sobre a temática na Base de dados Biblioteca Virtual de Saúde (BVS), que compreende pesquisas disponíveis nos seguintes sistemas: Literatura Latino Americana e do Caribe em Ciências de Saúde (LILACS), Sistema Online de Busca e Análise de Literatura Médica (MEDLINE), Base de dados bibliográfica especializada na área de Enfermagem (BDENF) e, Scientific Eletronic Library Online (SciELO).

Na busca, foram utilizados os seguintes termos-chave "Enfermagem", "Liderança" e "Estratégia Saúde da Família". Essa foi realizada a partir da combinação dos três termos, utilizando-se aspas para a definição exata do marcador e o apóstrofo booleano "and".

Os critérios de inclusão foram textos completos, em forma de artigos, disponíveis para download gratuitamente, em português e com o recorte temporal de 10 anos (2008-2017). Por sua vez, os de exclusão foram os documentos que não atenderam a proposta temática da revisão integrativa realizada e os duplicados. Os documentos encontrados através da busca foram contabilizados e expressos através de um fluxograma (Figura 1).

Figura 1 - Fluxograma da estratégia de busca da revisão integrativa em bases de dados.

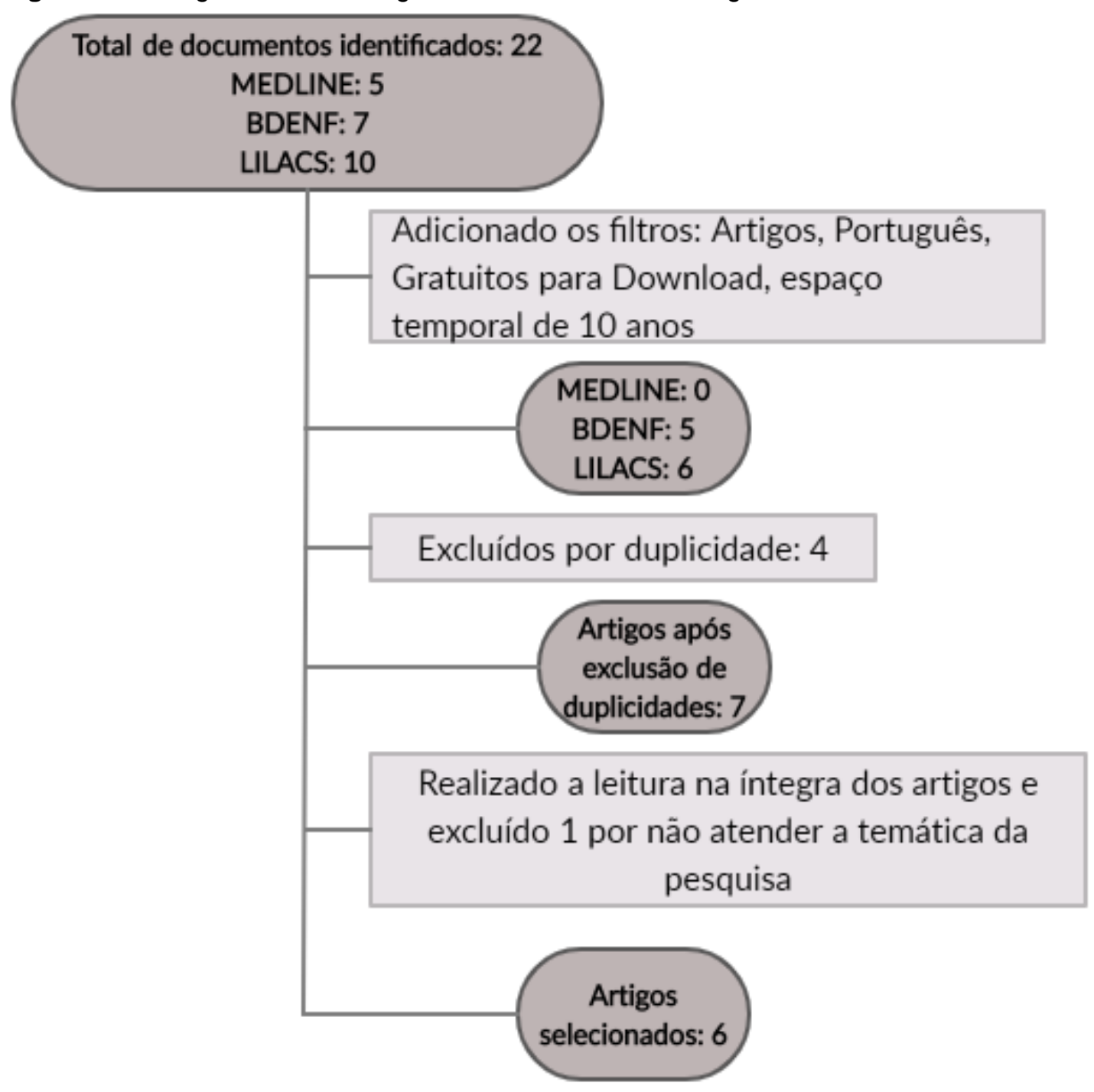

Fonte: Araújo JSF, et. al., 2019. 
$\mathrm{Na}$ terceira etapa na perspectiva de categorizar os estudos um quadro com a relação dos artigos selecionados foi elaborado, com as seguintes características de análise: codificação dos artigos, autores e título do estudo, ano e local da pesquisa, base de dados, objetivos, resultados principais e conclusão.

$\mathrm{Na}$ quarta etapa realizou-se a leitura na íntegra e avaliação de todos os estudos, sendo que uma análise criteriosa foi feita a partir do detalhamento de todas as seções das pesquisas publicadas (MENDES KDS, et al., 2008). Em seguida, através de uma segunda leitura dos estudos buscou-se organizar e agrupar em unidades de registro (UR) todas as palavras com afinidade à temática e com proximidade semântica.

Desta forma, as UR uma vez agrupadas, contribuíram para emergissem as categorias "a postura do líder e o estilo de liderança frente à equipe", "ouvir, diálogo e feedback entre os membros da equipe", "aspectos do serviço de saúde influenciadores da liderança", "e a "a relevância da educação permanente no preparo profissional".

\section{RESULTADOS E DISCUSSÃO}

O estudo a priori permitiu identificar a importância da ESF como porta preferencial e reorientadora do SUS, assim como do profissional enfermeiro para o desenvolvimento das ações preconizadas nesse ponto da rede de serviços de saúde.

A análise da Política Nacional de Atenção Básica (PNAB), documento que discorre sobre a organização e funcionamento da APS no País o enfermeiro emerge como responsável por planejar, gerenciar e avaliar as ações desenvolvidas pelos técnicos/auxiliares de enfermagem, Agentes Comunitários de Saúde (ACS) e Agentes de Controle de Endemias (ACE) em conjunto com os outros membros da equipe; e por supervisionar as ações do técnico/auxiliar de enfermagem e ACS o que converge para elucidar a relevância da liderança desse profissional (BRASIL, 2017). A pesquisa nas bases de dados não retornou resultados com publicações referentes à temática de liderança, enfermagem e ESF de forma agregada nos anos de 2008, 2009, 2010, 2011, 2014, 2017 (Quadro 1). 
Quadro 1 - Relação de estudos exportados das bases de dados.

\begin{tabular}{|c|c|c|c|c|c|c|}
\hline Autores & $\begin{array}{l}\text { Título do } \\
\text { periódico }\end{array}$ & Objetivos & Resultados principais & Conclusão & $\begin{array}{c}\text { Ano e } \\
\text { local da } \\
\text { pesquisa }\end{array}$ & $\begin{array}{c}\text { Base de } \\
\text { dados }\end{array}$ \\
\hline $\begin{array}{c}\text { COSTA EMS, } \\
\text { et al. }\end{array}$ & $\begin{array}{c}\text { Estilos de } \\
\text { liderança dos } \\
\text { enfermeiros que } \\
\text { atuam na } \\
\text { estratégia saúde } \\
\text { da família }\end{array}$ & $\begin{array}{c}\text { Relacionar as atividades } \\
\text { desenvolvidas pelos } \\
\text { enfermeiros que atuam na } \\
\text { ESF, em um município do sul } \\
\text { do Brasil com os principais } \\
\text { estilos de liderança } \\
\text { situacional, propostos pelo } \\
\text { modelo de Hersey e } \\
\text { Blanchard. }\end{array}$ & $\begin{array}{l}\text { Usou-se como base o modelo de } \\
\text { Hersey e Blanchard de liderança } \\
\text { situacional e os quatro estilos } \\
\text { propostos por eles ao final da } \\
\text { pesquisa ficam evidentes dois estilos } \\
\text { de liderança predominantes no } \\
\text { cenário pesquisado, este resultado } \\
\text { se dá pelo perfil da equipe estudada. }\end{array}$ & $\begin{array}{l}\text { O processo de delegar e observar a } \\
\text { execução de tarefas deve ser exercido } \\
\text { pelo enfermeiro líder da equipe a fim } \\
\text { de identificar o nível de maturidade } \\
\text { dos seus liderados. Lembrar que a } \\
\text { maturidade é variável e que tal pode } \\
\text { ser desenvolvida e aprimorada. }\end{array}$ & $\begin{array}{c}2015 \\
\text { Município } \\
\text { do Sul do } \\
\text { Brasil }\end{array}$ & BDENF \\
\hline $\begin{array}{c}\text { SPAGNUOLO } \\
\text { RS, et al. }\end{array}$ & $\begin{array}{l}\text { O enfermeiro e } \\
\text { a estratégia } \\
\text { saúde da } \\
\text { família: desafios } \\
\text { em coordenar a } \\
\text { equipe } \\
\text { multiprofissional }\end{array}$ & $\begin{array}{l}\text { Compreender o papel do } \\
\text { enfermeiro no exercício da } \\
\text { coordenação de uma equipe, } \\
\text { em relação às competências e } \\
\text { habilidades praticadas e } \\
\text { desenvolvidas no seu } \\
\text { cotidiano de trabalho, e às } \\
\text { dificuldades em exercer essa } \\
\text { função. }\end{array}$ & $\begin{array}{l}\text { Foram evidenciadas as dificuldades } \\
\text { vivenciadas por enfermeiros na } \\
\text { coordenação de equipes pelo } \\
\text { desconhecimento e despreparo } \\
\text { profissional, levando a sobrecarga } \\
\text { de trabalho, a incompreensão da } \\
\text { população sobre os princípios da } \\
\text { ESF, afetando o processo de } \\
\text { trabalho e a falta de autonomia em } \\
\text { seu ambiente de trabalho sem o } \\
\text { apoio da gestão. }\end{array}$ & $\begin{array}{l}\text { O estudo deu visibilidade a alguns } \\
\text { desafios enfrentados no tocante à } \\
\text { coordenação da ESF, revelando o } \\
\text { despreparo profissional, sobrecarga } \\
\text { de trabalho, a sobreposição de } \\
\text { tarefas, a desvalorização profissional, } \\
\text { a falta de capacitação, cobrança por } \\
\text { produtividade que promove a } \\
\text { desvalorização profissional. }\end{array}$ & $\begin{array}{l}2012 \\
\text { Município } \\
\text { do interior } \\
\text { do estado } \\
\text { de São } \\
\text { Paulo. }\end{array}$ & LILACS \\
\hline LIMA FS, et al. & $\begin{array}{l}\text { Exercício da } \\
\text { liderança do } \\
\text { enfermeiro na } \\
\text { estratégia saúde } \\
\text { da família }\end{array}$ & $\begin{array}{l}\text { Conhecer o exercício da } \\
\text { liderança do enfermeiro na } \\
\text { estratégia saúde da família, } \\
\text { bem como as dificuldades e } \\
\text { estratégias adotadas pelos } \\
\text { enfermeiros para liderar. }\end{array}$ & $\begin{array}{l}\text { A pesquisa identificou o enfermeiro } \\
\text { líder no contexto da ESF estando } \\
\text { associado ao profissional de } \\
\text { referência e exemplo para os demais } \\
\text { membros da equipe, sendo a postura } \\
\text { profissional e a motivação } \\
\text { características essenciais para o } \\
\text { exercício da liderança. }\end{array}$ & $\begin{array}{c}\text { O estudo identificou fragilidades no } \\
\text { apoio pela gestão municipal, } \\
\text { incompreensão da equipe e } \\
\text { dificuldades relacionais como barreiras } \\
\text { para o desenvolvimento eficiente do } \\
\text { líder no cotidiano, destacando o } \\
\text { diálogo e o trabalho em equipe como } \\
\text { elementos necessários para a } \\
\text { liderança. }\end{array}$ & $\begin{array}{l}2016 \\
\text { Pelotas, } \\
\text { Rio } \\
\text { Grande } \\
\text { do Sul. }\end{array}$ & LILACS \\
\hline
\end{tabular}

REAS/EJCH | Vol.Sup.n.58 | e4326 | DOI: https://doi.org/10.25248/reas.e4326.2020 Página $\mathbf{5}$ de 10 
Revista Eletrônica Acervo Saúde / Electronic Journal Collection Health | ISSN 2178-2091

\begin{tabular}{|c|c|c|c|c|c|c|}
\hline Autores & $\begin{array}{l}\text { Título do } \\
\text { periódico }\end{array}$ & Objetivos & Resultados principais & Conclusão & $\begin{array}{c}\text { Ano e } \\
\text { local da } \\
\text { pesquisa }\end{array}$ & $\begin{array}{c}\text { Base de } \\
\text { dados }\end{array}$ \\
\hline $\begin{array}{l}\text { PAULA M, et } \\
\text { al. }\end{array}$ & $\begin{array}{l}\text { Processo de } \\
\text { trabalho e } \\
\text { competências } \\
\text { gerenciais do } \\
\text { enfermeiro da } \\
\text { Estratégia } \\
\text { Saúde da } \\
\text { Família }\end{array}$ & $\begin{array}{l}\text { Identificar às dimensões do } \\
\text { processo de trabalho do } \\
\text { enfermeiro na ESF, e } \\
\text { correlacionar as competências } \\
\text { necessárias para o } \\
\text { desenvolvimento de atividades } \\
\text { gerenciais. }\end{array}$ & $\begin{array}{l}\text { A pesquisa classificou o processo de } \\
\text { trabalho em diferentes dimensões, } \\
\text { ressaltando as competências gerais } \\
\text { desenvolvidas pelos enfermeiros } \\
\text { estão interligadas com funções } \\
\text { administrativas. Após o } \\
\text { detalhamento das competências } \\
\text { gerenciais gerais foi decidido } \\
\text { subdividi-las em competências } \\
\text { gerais específicas. }\end{array}$ & $\begin{array}{l}\text { Observou-se o tempo dedicado pelo } \\
\text { enfermeiro em suas diferentes } \\
\text { dimensões. Interligando funções } \\
\text { gerenciais com administrativas. } \\
\text { Evidenciando dentre as competências } \\
\text { gerenciais necessárias para o } \\
\text { desenvolvimento das atividades na } \\
\text { unidade, sendo as mais utilizadas, a } \\
\text { comunicação e a liderança. }\end{array}$ & $\begin{array}{l}2013 \text { Sul } \\
\text { do Brasil. }\end{array}$ & BDENF \\
\hline $\begin{array}{l}\text { LANZONI } \\
\text { GMM e } \\
\text { MEIRELLES } \\
\text { BHS. }\end{array}$ & $\begin{array}{l}\text { Liderança do } \\
\text { enfermeiro: } \\
\text { elemento } \\
\text { interveniente na } \\
\text { rede de } \\
\text { relações do } \\
\text { agente } \\
\text { comunitário de } \\
\text { saúde }\end{array}$ & $\begin{array}{l}\text { Compreender as contribuições } \\
\text { do enfermeiro na rede de } \\
\text { relações e interações dos ACS } \\
\text { de um município localizado ao } \\
\text { sul do país. }\end{array}$ & $\begin{array}{l}\text { Identificou o profissional enfermeiro } \\
\text { como mediador das relações e } \\
\text { interações, subdividido em dois } \\
\text { momentos: O enfermeiro como líder: } \\
\text { é indicado como o profissional } \\
\text { fundamental para o funcionamento } \\
\text { da unidade de saúde. Como ponte } \\
\text { de Comunicação: este profissional é } \\
\text { reconhecido assim por estar sempre } \\
\text { atento e bem informado. }\end{array}$ & $\begin{array}{l}\text { Conclui-se que a equipe de saúde } \\
\text { compreende o profissional enfermeiro } \\
\text { como um elemento significativo na } \\
\text { rede de relações e interações, sendo } \\
\text { visualizado como mediador e como } \\
\text { uma liderança. Promovendo a } \\
\text { interlocução e agindo como um } \\
\text { facilitador do trabalho em equipe na } \\
\text { promoção da saúde da comunidade. }\end{array}$ & $\begin{array}{l}2013 \\
\text { Sul do } \\
\text { Brasil. }\end{array}$ & LILACS \\
\hline $\begin{array}{l}\text { ROCHA BS e } \\
\text { MUNARI DB. }\end{array}$ & $\begin{array}{l}\text { Avaliação da } \\
\text { competência } \\
\text { interpessoal de } \\
\text { enfermeiros } \\
\text { coordenadores } \\
\text { de equipe na } \\
\text { saúde da } \\
\text { família. }\end{array}$ & $\begin{array}{l}\text { Verificar como o enfermeiro da } \\
\text { ESF avalia sua competência } \\
\text { interpessoal para a } \\
\text { coordenação da equipe. }\end{array}$ & $\begin{array}{l}\text { O estudo apontou que o processo de } \\
\text { trabalho dos enfermeiros } \\
\text { coordenadores de equipe e a } \\
\text { liderança efetiva são prejudicados } \\
\text { quando se tem ausência de algumas } \\
\text { competências como, influenciar } \\
\text { pessoas, lidar com conflitos da } \\
\text { equipe e receber críticas e feedback. }\end{array}$ & $\begin{array}{c}\text { Considerando as habilidades } \\
\text { interpessoais como sendo } \\
\text { indispensáveis para a liderança efetiva } \\
\text { e eficaz os enfermeiros coordenadores } \\
\text { de equipes necessitam sanar suas } \\
\text { limitações pessoais, criando espaços } \\
\text { e atividades que lhes possibilita refletir } \\
\text { e desenvolver melhor sua } \\
\text { competência interpessoal. }\end{array}$ & $\begin{array}{c}2013 \\
\text { Goiana/ } \\
\text { Goiás }\end{array}$ & BDENF \\
\hline
\end{tabular}

Fonte: Araújo JSF, et. al., 2019

REAS/EJCH | Vol.Sup.n.58 | e4326 | DOI: https://doi.org/10.25248/reas.e4326.2020 Página 6 de 10 
O ano de 2013 destacou-se por devolver como resultado três (3) artigos totalizando 50\% dos resultados. Foi possível compreender que essa distribuição temporal dos artigos analisados remete a uma elevação no quantitativo de publicações envolvendo essa temática, sobretudo nos últimos 5 anos. Quanto ao local de publicação dos artigos selecionados, $67 \%(n=4)$ foram publicados no Sul do Brasil, $16,5 \%(n=1)$ no Sudeste, e $16,5 \%$ ( $n=1)$ no centro-oeste.

O processo de trabalho do enfermeiro na ESF tem como característica ser denso por conta das atividades com desenhos específicos que exige do mesmo além do saber técnico, maleabilidade, atenção e empatia. $\mathrm{Na}$ prática a liderança exercida por este profissional torna-se efetiva quando é capaz de influenciar outros membros da equipe, moldar atitudes e promover integração. A exposição óptica da imagem do enfermeiro como líder é capaz de gerar em seus liderados a aspiração de segui-lo. No que o exercício da liderança acaba por afetar diretamente a cultura organizacional, resultando em um processo de trabalho mais coeso e na qualidade da assistência prestada (LANZONI GMM e MEIRELLES BHS, 2013; PAULA M, et al., 2013; ROCHA BS e MUNARI DB, 2013; COSTA EMS, et al., 2015).

Neste sentido, a habilidade de ordenamento significativo da realidade e suas ressonâncias no imaginário coletivo é o que constitui a força do líder e fundamenta o exercício legítimo da sua influência (DAVEL E; MACHADO HV, 2001).

O líder emerge como consequência da necessidade de um grupo, que para produção de determinadas ações precisa ser orientado (KNICKERBOCKER I, 1961). Por sua vez, o exercício da liderança pelo enfermeiro pode gerar uma carga excessiva de trabalho, visando à produção e não a qualidade da assistência prestada (SPAGNUOLO RS, et al., 2012; LIMA FS, et al., 2016). Assim, a postura do líder e o estilo da liderança frente às equipes são determinantes para o direcionamento do processo de trabalho e orientação das diferentes ações desenvolvidas pelos profissionais da ESF.

A liderança e seus estilos podem ser identificados através da postura profissional de quem exerce esta função ou se encontra nessa posição. O comportamento dos sujeitos implica que o líder adote um estilo de liderança específico adequado às características desse grupo (SILVA PMS, 2017). Desta forma, os estilos de liderança só podem ser definidos de acordo com as características da equipe e seu nível de maturidade, que é determinada pelo estímulo ao aprimoramento das habilidades de seus membros (ROCHA BS e MUNARI DB, 2013; COSTA EMS, et al., 2015).

O líder deve ser capaz de delegar funções, avaliar a execução das atividades e identificar fatores que implicam na resolutividade das ações, tais como, disposição física, capacidade técnica, conhecimento por parte dos profissionais das suas atribuições e respeito às hierarquias existentes. A liderança é vista como imprescindível para o gerenciamento, o que confirma ser esta uma habilidade necessária para o enfermeiro da ESF (SPAGNUOLO RS, et al., 2012; PAULA M, et al., 2013; ROCHA BS e MUNARI DB, 2013; COSTA EMS, et al., 2015).

Dentre as atribuições desse profissional estão a de "planejar, gerenciar e avaliar as ações desenvolvidas pelos ACS em conjunto com os outros membros da equipe, "participar do gerenciamento dos insumos necessários para o adequado funcionamento da UBS" e "coordenar a equipe, influenciando no alcance das metas" (LANZONI GMM e MEIRELLES BHS, 2013; BRASIL, 2017).

A motivação como uma potente ferramenta para o exercício da liderança, consiste no conjunto de forças internas que mobiliza o indivíduo para atingir um dado objetivo como resposta a um estado de necessidade, carência ou desequilíbrio (PEDROSO DOO, 2012).

O líder deve motivar a equipe para que haja ímpeto na realização do trabalho; deve reconhecer sempre que necessário as aptidões dos profissionais, contribuindo para criação de uma rede de satisfação profissional; deve observar e estimular necessidades de aperfeiçoamento; e deve ser exemplar, servindo de referência aos seus liderados (ROCHA BS e MUNARI DB, 2013; LIMA FS, et al., 2016).

O enfermeiro como líder é mediador das relações entre equipe e comunidade e no exercício da liderança responde pela resolução de eventuais conflitos que vierem a surgir (LANZONI GMM e MEIRELLES BHS, 2013; PAULA M, et al., 2013; COSTA EMS, et al., 2015; LIMA FS, et al., 2016). 
Esses, se não forem administrados de forma adequada, podem acabar gerando desmotivação e levar a organização à estagnação. Assim, visão aguçada, cautela, imparcialidade e equilíbrio são características importantes do líder que gerencia conflitos apontam a relevância da liderança como ferramenta para resolução de conflitos por este profissional (ASSIS AF e STRAUB A, 2016).

A atuação na vanguarda administrativa da equipe e nos tratos com a comunidade leva o enfermeiro a presenciar situações diversas quanto à origem, complexidade e resolutividade. As experiências vivenciadas por ele a depender do estilo de liderança adotado coopera para a criação de uma bagagem ampla de conhecimento que vai além do conhecimento técnico-científico, gerando um constante aprendizado (SPAGNUOLO RS, et al., 2012; LIMA FS, et al., 2016). No entanto, os estilos de liderança não foram evidenciados como entrave ou facilitador para o exercício da liderança, mas como uma habilidade e ferramenta que contribuem para o seu processo de trabalho (COSTA EMS, et al., 2015).

A comunicação é vista como elemento essencial para o processo de trabalho, podendo afetar os processos gerenciais, a depender de como ela ocorre, sendo um entrave para a liderança (SPAGNUOLO RS, et al., 2012; COSTA EMS, et al., 2015; LIMA FS, et al., 2016). Diante disso, o ouvir, diálogo e feedback entre os membros da equipe são necessários no que tange a liderança pelo enfermeiro na ESF.

O desenvolvimento de práticas dialógicas contribui para a promoção de autonomia dos sujeitos, sendo um componente que favorece o comprometimento e melhoria do comportamento dos membros da equipe (COSTA EMS, et al., 2015).

Nesta ótica, o ouvir e o diálogo são aptidões esperáveis do enfermeiro líder no desenvolvimento da comunicação e fundamentais para a liderança por serem facilitadores do trabalho em equipe (LANZONI GMM e MEIRELLES BHS, 2013; PAULA M, et al., 2013; ROCHA BS e MUNARI DB, 2013; LIMA FS, et al., 2016).

A comunicação apresenta-se como elemento decisório para o desenvolvimento do grupo e indispensável ao processo de gerenciamento (PAULA M, et al., 2013; ROCHA BS e MUNARI DB, 2013). O enfermeiro emerge como ponte para comunicação eficiente entre a equipe e usuários, contribuindo para promoção da efetividade assistencial; e como elemento produtor de interlocução de informações relevantes que contribuem para o desenvolvimento das diferentes atividades que são realizadas na ESF (LANZONI GMM e MEIRELLES BHS, 2013; PAULA M, et al., 2013).

Segundo Leopardi MT (2006) a dificuldade para comunicação entre os membros da equipe deriva de questões pessoais, sociais e ideológicas tornando o processo de trabalho denso e as relações frágeis. 0 enfermeiro é parte integrante da equipe de saúde e como tal deve se ocupar em manter o equilíbrio dinâmico, prevenir desequilíbrios e reverter desequilíbrios em equilíbrio. Assim, a adoção de uma comunicação verticalizada pode ser um entrave para o exercício da liderança por parte deste profissional (LANZONI GMM e MEIRELLES BHS, 2013).

Já, no que concerne a comunicação como parte integradora das atividades gerenciais, a alternância de profissionais de saúde tende a ser um entrave para a liderança (SPAGNUOLO RS, et al., 2012). O líder se torna parâmetro e referência para seus liderados, ditando certas características e orientando a da práxis em saúde, no que a rotatividade dele, pode contribuir para rupturas no processo dialógico, ruídos, e principalmente, fragmentação do cuidado em saúde.

Na ESF o enfermeiro se destaca como líder em todo o processo de trabalho (LIMA FS, et al., 2016). Ele exerce atribuições específicas assistenciais e atribuições pertinentes ao gerenciamento e coordenação (BRASIL, 2017). Os aspectos do serviço de saúde influenciadores da liderança podem ser variados, mas possuem como ponto de convergência, serem passíveis de ajustamentos.

A sobreposição de tarefas foi identificada como um aspecto do serviço de saúde que influencia na liderança, gerando aumento das cargas de trabalho e implicando na qualidade dos cuidados prestados (SPAGNUOLO RS, et al., 2012; LANZONI GMM e MEIRELLES BHS, 2013).

As cargas de trabalho são elementos identificados no desenvolvimento do trabalho capazes de produzir desgaste no trabalhador, influenciando no desempenho de suas funções (SCHERER MDA, et al., 2016), 
podendo ser produzidas por dilemas relacionados às atividades do trabalhador ou da gestão municipal; frágil gerenciamento dos insumos necessários para o funcionamento dos serviços; e excesso de demanda (SPAGNUOLO RS, et al., 2012; PAULA M, et al., 2013; LIMA FS, et al., 2016).

Na prática da ESF o excesso de demanda pode ser visto como o descompasso entre as necessidades que emergem e a capacidade da equipe em respondê-las (SCHERER MDA, et al., 2016). O enfermeiro como líder responde pela gestão das agendas de atendimento na ESF e deve orientar o acesso ofertando atendimento individual e coletivo nas modalidades de cuidado preventivo, promocional e curativo (BRASIL, 2017).

$\mathrm{Na}$ organização das agendas esse profissional deve ter como foco não somente as demandas programadas, mas também, as espontâneas, visando reorganizar o cuidado em saúde e diminuir a carga de trabalho sobre os profissionais (SPAGNUOLO RS, et al., 2012).

A carga de trabalho relacionada à demanda populacional converge para manutenção de um modelo de atenção que tem como foco a produtividade em detrimento da qualidade das ações em saúde, acarreta na desvalorização do profissional enfermeiro e cria obstáculos para o exercício da sua liderança (LIMA FS, et al., 2016).

O desgaste que ela produz priva esse profissional de exercer integralmente sua liderança e tende a ser naturalizado no cotidiano do trabalho (BIFF D, 2016). Assim, faz-se necessário maior investimento no cuidado e na valorização desse trabalhador.

As atividades de educação permanente na ESF podem fortalecer grandemente o desenvolvimento das atribuições de gestão e de cuidado, uma vez que ampliam os caminhos para o enfrentamento dos obstáculos vivenciados pelos profissionais, formas de investimento no cuidado e estratégia de valorização profissional (BRASIL, 2017). No que, a relevância da educação permanente no preparo profissional é de extrema importância para o exercício da liderança pelo enfermeiro.

A ausência ou deficiência de educação permanente é encarada como um entrave para o bom desenvolvimento do trabalho em equipe, estando relacionada à sobrecarga de trabalho (SPAGNUOLO RS, et al., 2012) e a alta demanda de usuários para atendimento (VIANA DM, et al., 2015).

No contexto da ESF, relevo deve ser dado à educação permanente, não só por sua importância pedagógica, mas também, por ser uma potente "estratégia de gestão" com ampla capacidade de ocasionar mudanças. Dessa forma, ao enfermeiro que ocupa papel de líder neste cenário de cuidado em saúde compete além das atividades de supervisão e coordenação, a realização de atividades de educação permanente (BRASIL, 2017).

Para atuação na ESF é imprescindível que os profissionais tenham uma compreensão ampliada acerca dos instrumentos que permitem intervir nas carências em saúde da população. Desta forma, a educação permanente como uma competência gerencial a ser desenvolvida pelo enfermeiro torna-se necessária para desdobramento de atividades que culminem no desenvolvimento de competências e atualização dos outros integrantes da equipe (PAULA M, et al., 2013).

A falta de apoio da gestão municipal nas políticas e ações voltadas para educação permanente é tida como um entrave para o exercício da liderança pelo enfermeiro, que envolvido com outras atividades disparadas pela gestão acaba não tendo espaço e tempo para repensar a produção do cuidado e o processo de trabalho dos seus liderados, culminando em ações de saúde pouco resolutivas, déficit de conhecimento científico e diminuição da qualidade da assistência (VIANA DM, et al., 2015; LIMA FS, et al.,2016).

A escassez de estudos e pesquisas sobre educação permanente relacionada à liderança do enfermeiro se mostra como um entrave para o desenvolvimento de competências do profissional enfermeiro e sinaliza necessidade de investimento em pesquisa nessa área, assim como desenvolvimento de estratégias no cotidiano dos serviços de saúde que contribuam para o a capacitação e aperfeiçoamento dos mesmos, principalmente aqueles que desenvolvem atividades de liderança. 


\section{CONSIDERAÇÕES FINAIS}

A interação social fragilizada no ambiente de trabalho emergiu como fator que gera entrave na liderança do enfermeiro na ESF. Já, o desenvolvimento da autonomia desse profissional, como um facilitador. No entanto, para o alcance da autonomia o enfermeiro precisa ter conhecimento ampliado sobre o seu processo de trabalho, dos diferentes papéis que desenvolve, assim como, da posição que ocupa os outros membros da equipe de saúde. Ademais, observa-se escassez de produção científica referente à temática liderança na ESF, trazendo relevo para a necessidade de produção do conhecimento sobre o assunto e fomento do debate nos cursos de graduação e pós graduação.

\section{REFERÊNCIAS}

1. ASSIS AF, STRAUB A. Gestão de conflitos: a oportunidade de aprendizagem através da exploração de divergências. Revista da Fae. 2016; 19 (2): 220-231.

2. BIFF D. Cargas de trabalho de enfermeiros da Estratégia Saúde da Família. Tese (Doutorado em Enfermagem) Programa de Pós-Graduação em Enfermagem. Universidade Federal de Santa Catarina, Florianópolis, 2016; 245p.

3. BRASIL. Portaria oㅡ 2.436, de 21 de setembro de 2017. Aprova a Política Nacional de Atenção Básica (PNAB), estabelecendo a revisão de diretrizes para a organização da Atenção Básica, no âmbito do Sistema Único de Saúde (SUS). Diário Oficial da União 2017; 22 set.

4. BRASIL. Lei no 7.498 de 25 de junho de 1986. Dispõe sobre a regulamentação do exercício da Enfermagem e dá outras providências. Brasília; 1986.

5. CHIAVENATO I. Gerenciando com pessoas: transformando o executivo em um gestor de pessoas: um guia para o executivo aprender a lidar com a sua equipe de trabalho. São Paulo: Manole, 2014.

6. COSTA EMS, PERES AM, BERNARDINO E, SADE PMC. Estilos de liderança dos enfermeiros que atuam na Estratégia Saúde da Família. Ciência, Cuidado e Saúde. 2015; 14 (1): 962-969.

7. DAVEL E, MACHADO HV. A dinâmica entre liderança e identificação: sobre a influência consentida nas organizações contemporâneas. Revista de Administração Contemporânea. 2001; 5 (3): 107-126.

8. FERREIRA ABH. Novo dicionário Aurélio da Língua Portuguesa. 5a ed. Curitiba: Positivo, 2010.

9. KNICKERBOCKER I. Liderança: uma conceituação e algumas implicações. Rev. adm. empres. [online]. $1961 ; 1$ (2): 137-161.

10. KURCGANT P, PERES HHC, CIAMPONE MHT. A liderança na Administração do Pessoal de Enfermagem segundo a Percepção de Enfermeiras, Auxiliares e Atendentes de Enfermagem. Rev. esc. enferm. USP. 1996; 30 (3): $416-438$.

11. LANZONI GMM, MEIRELLES BHS. Liderança do enfermeiro: elemento interveniente na rede de relações do agente comunitário de saúde. Revista Brasileira de Enfermagem. 2013; 66 (4): 557-563.

12. LEOPARDI MT. Teoria e método em assistência de enfermagem. $2^{\underline{a}}$ ed. Florianópolis: Soldasof, 2006.

13. LIMA FS, AMESTOY SC, JACONDINO MB, TRINDADE LL, SILVA CN, JUNIOR PRBF. Exercício da liderança do enfermeiro na estratégia saúde da família. Revista online de Pesquisa Cuidado é Fundamental. 2016 ; 8 (1): 3893 3606.

14. MENDES KDS, SILVEIRA RCCP, GALVÃO CM. Revisão integrativa: método de pesquisa para a incorporação de evidências na saúde e na enfermagem. Texto contexto - enferm. 2008; 17 (4): 758-64.

15. PAULA M, PERES AM, BERNARDINO E, EDUARDO EA, MACAGI STS. Processo de trabalho e competências gerenciais do enfermeiro da Estratégia saúde da família. Revista da Rede de Enfermagem do Nordeste. $2013 ; 14$ (5): 1-8.

16. PEDROSO DOO, FRANÇA NS, OSAWA JLT, OLIVEIRA SS. Importância da Motivação dentro das Organizações. Revista Ampla de Gestão Empresarial. 2012; 5 (1): 60-76.

17. PINTO LF, GIOVANELLA L. Do Programa à Estratégia Saúde da Família: expansão do acesso e redução das internações por condições sensíveis à atenção básica (ICSAB). Ciênc Saúde Coletiva. 2018; 23(6):1903-1914.

18. ROCHA BS, MUNARI DB. Avaliação da competência interpessoal de enfermeiros Coordenadores de equipe na saúde da família. Revista de Enfermagem e Atenção à Saúde. 2013; 2 (3): 53-66.

19. SCHERER MDA, OLIVEIRA NA, PIRES DEP, TRINDADE LL, GONÇALVES ASR, VIEIRA, M. Aumento das cargas de trabalho em técnicos de enfermagem na atenção primária à saúde no Brasil. Trabalho, Educação e Saúde. 2016; 14(1): 89-104.

20. SILVA PMS. O Papel Do Líder Na Motivação Da Equipe. Centro De Pós Graduação Oswaldo Cruz, S.D. 2017.

21. SPAGNUOLO RS, JULIANI CMCM, SPIRI WC, BOCCHI SCM, MARTINS STF. O enfermeiro e a estratégia saúde da família: desafios em coordenar a equipe multiprofissional. Ciência, Cuidado e Saúde. 2012; 11 (2): 226-234.

22. TEIXEIRA CF. A mudança do modelo de atenção à saúde no SUS: desatando nós, criando laços. Saúde em debate. 2006; 27 (65): 257-277.

23. VIANA DM, NOGUEIRA CA, ARAÚJO RS, VIEIRA RM, RENNÓ HMS, OLIVEIRA VC. A educação permanente em saúde na perspectiva do enfermeiro na estratégia de saúde da família. Revista de Enfermagem do Centro Oeste Mineiro. 2015; 5 (2): 1658-1668. 